\title{
Analysis of the Influence of Hot Impacts on the Transformation of White Cast Iron
}

\author{
Ekbal Mohammed Saeed Salih*, Ahmed Ouda Al-Roubaiy, Yasser Louy Azeez Salih
}

Materials Engineering, Department of Metallurgical Engineering, University of Babylon, Babil, Hilla 51002, Iraq

Corresponding Author Email: mat.ekbal.moh@uobabylon.edu.iq

https://doi.org/10.18280/acsm.450104

Received: 7 September 2020

Accepted: 21 December 2020

\section{Keywords:}

mechanical heat treatment, white cast iron, hot impact, cementite, graphite flakes, gray cast iron, cast iron, hot deformation

\begin{abstract}
Heat treatments are the most common method of transforming or modifying the structure of white cast iron. Cementite tapes can be decomposed at high temperatures and over a long period of time. These thermal treatments require special furnaces and a long period of time, as well as a high cost with major problems associated with these techniques. In this study, a mechanical thermal treatment was employed, which includes two basic stages, the first being heating at a certain temperature $1100^{\circ} \mathrm{C}$ for a rather short period of time, then applying sequential strokes (one stroke or group of strokes) for a period not exceeding a few minutes. The findings proved that heating for short or long periods of time and at $1100^{\circ} \mathrm{C}$ is not sufficient to get rid of cementite tapes, as the structure remained white cast iron. The important matter here is that the effect of the hot impact on the transformation of white cast iron into grey is related to the formation ratio. In this regard, the results uncover that using hot impact and at the same temperature, but at higher rates of forming (i.e., greater than 70\%) the structure is completely transformed into grey cast iron.
\end{abstract}

\section{INTRODUCTION}

Cast iron is a type of ferrous alloy which typically contains carbon in a percentage greater than around $(2.14 \mathrm{wt} \% \mathrm{C})$. Casting is the only way to produce it, which is why it is called cast iron [1]. In general, much of the cast iron contains carbon (3-4.5 wt \% C) in addition to other casting elements [2]. Compared to steel, its ductility is often poor and typically created by blacksmithing or hot forming. In spite of this, cast iron has many benefits, including its low cost, low melting degrees $\left(1140-1200^{\circ} \mathrm{C}\right)$ relative to steel, high fluidity in wide and complicated casting molds, high wear resistance and high damping power in addition to high compressive strength and other qualities [3].

Cast iron has two basic types depending on the nature of the relationship between carbon and iron. The first is white cast iron, which is characterized by its hardness and high wear resistance, but is inoperable, and the second type is gray cast iron, which has better operational properties than white. The metallurgical characteristics exhibited by white is what has added certain qualities where carbon binds to iron forming a dense network of cementite $\left(\mathrm{Fe}_{3} \mathrm{C}\right)$ and this compound is distinguished by high hardness with lost ductility. Therefore, this type of cast iron is inoperable and its uses are very limited, such as those used for crushing and grinding machines [4]. As far as gray is concerned, it has stronger working properties than white, since carbon here is free deposited in the form of thin flakes of graphite in pearlite, ferrite or even martensite floors, depending on the cooling factor associated with its deposition [5]. White cast iron, despite its high mechanical properties, its lack of ductility restricted its use [5].

Numerous studies have been conducted to study the effect of thermal treatments (being the only method) in modifying and changing the metallurgical structure of white in order to improve its properties, especially ductility, and convert it into cast iron malleable and ductile and at the same time retain other mechanical properties in a very reasonable manner. In this way, it is used in the automotive industry, wheel huts, fitting parts for petrol, water or air, as well as for the repairing of bicycle tires and parts of agricultural and textile machinery $[6,7]$.

Chen and Li [8] studied the effect of different tempering temperatures on the microstructure and mechanical properties of high boron white cast iron after air quenching. their findings showed that the optimum structure that has a combination of high hardness and high impact toughness can be obtained when the tempering temperature is lower than $400^{\circ} \mathrm{C}$. The results reported by Abdel-Aziz et al. [9] revealed that the addition of alloys with appropriate amounts of carbide forming elements to high $\mathrm{Cr}$ white cast irons marked improvements in mechanical properties and wear performance through microstructure refining and in situ formation of fine new carbides.

Zeytin et al. [10] applied heat treatment methods to white cast iron for improving the impact and wear resistance and concluded that heat treatment provided higher wear and hardness properties, compared to the standard heat treatment.

Zhou et al. [11] studied the effect of heat treatments on the microstructure, hardness, toughness, and wear resistance of high chromium cast iron to determine the optimal heat treatment process. The results showed that with a rise in the quenching temperature from $950^{\circ} \mathrm{C}$ to $1050^{\circ} \mathrm{C}$, the hardness of high chromium cast iron increased to a certain value, was preserved for a period of time and then decreased. In same regard, Fernández and Belzunce [12] studied two heat treated high-chromium white cast irons with different carbon contents using compression at $500^{\circ} \mathrm{C}$, and wear and oxidation tests at 500 and $600^{\circ} \mathrm{C}$. 
Gelfi et al. [13] investigated the effect of each heat treatment on the microstructure of the alloys by optical and scanning electron microscope and X-ray diffraction analysis. The study claimed that in case of high-chromium white irons, the destabilization heat treatment $\left(950^{\circ} \mathrm{C}-2 \mathrm{~h}\right)$ produced a hard martensitic matrix with secondary carbides that gave superior erosion resistance compared to all other conditions. Opapaiboon et al. [14] studied the effect of chromium $(\mathrm{Cr})$ content on heat treatment behaviour of multi-alloyed white cast iron and reported that in the tempered state, evident secondary hardening was observed in all specimens.

Inthidech et al. [15] investigated the effect of tungsten equivalent on hardness and volume fraction of retained austenite of heat-treated semi-multi-alloyed white cast irons. Their results indicated that in tempered state, the hardness curves showed an evident secondary hardening due to the precipitation of secondary carbides and the transformation of retained austenite to martensite. Meebupha et al. [16] studied the effect of the Molybdenum content on the heat treatment behaviour of multi-alloyed white cast iron and found that the hardness in the as-hardened state was increased progressively with an increase in the Molybdenum content. Sarac and Dikici [17] showed that after heat treatment higher wear resistance and hardness were achieved thanks to the thinned and elongated primary carbides, excessive amount of secondary carbides and the martensitic matrix.

Heat treatments are the only method used to enhance the properties of cast Iron. It requires heating stages, elevated temperatures for long stretches of time, and in special atmospheres for converting to cast iron paths. These treatments are distinguished by long durations, elevated temperatures, high costs, and the deficiencies and complications that surround them [18].

Sil'man et al. [19] studied the influence of thermal treatments on the structure and properties of white in the presence of elements such as (Mn, V). Stan et al. [20] employed the thermal analysis (cooling curve) to compare hypoeutectic grey (lamellar graphite) and ductile (nodular graphite) cast irons solidification patterns. In order to obtain a better experimental condition and improve surface hardness, García-León et al. [21] developed different thermal treatments on nodular grey cast iron. Using thermomechanical treatment technology, Abdellah et al. [22] researched how enhance the ductility and flow behavior of cast iron without change in the chemical composition.

Kante et al. [23] discussed the impact of low temperature annealing of cast irons on the combined electron beam in addition to nitriding treatments Jia et al. [24] researched the impact of tempering (with in-situ analysis in multiple cycles) on resistance (wear, toughness and durability) by alternate water quenching and air cooling. As far as thermoelectric parameters are concerned, their effect has been observed, which involves hot shock in the attempt to curl white and transform it into gray, thereby reducing the problems of conventional thermal treatments.

Liu et al. [25] done an experimental study to investigate the transformation mechanism of graphite phase and microstructure in a laser cladding heated region. The findings showed that, with the exception of the refined graphite size, the morphological characteristics of graphite substrate and graphite in the heat-affected zone were similar. Under given heat-treatment conditions, Chen et al. [26] studied the effect of niobium addition on the graphite microstructure, bainite microstructure, bainite transformation process and properties such as hardness and impact toughness. The said study found that niobium addition in the range of $0.2-0.5 \mathrm{wt}$ percent allows obtaining an optimum combination of hardness, impact toughness and wear resistance.

Furthermore, several studies have been focused on thermal treatment in different application [27, 28].

The present study represents an attempt to transform white cast iron to gray with the help of mechanical thermal treatment, in which white cast iron samples are exposed to $\left(1100^{\circ} \mathrm{C}\right)$ and for a specific period of time, to direct knocking for a time or several times. Also, the effect of percent formation percentages on the transformation process was studied through microscopy and $\mathrm{x}$-ray examination.

\section{EXPERIMENTAL PROCEDURES}

White cast iron alloy was prepared from high purity metals and used induction furnaces for the smelting process and the temperature was $1398^{\circ} \mathrm{C}$, then poured into cylindrical sand molds with dimensions $(30 \mathrm{~mm}$ in diameter and $70 \mathrm{~mm}$ in thickness). Table 1 shows the chemical composition of white cast iron used for this study.

Table 1. Chemical composition of white cast Iron

\begin{tabular}{cccccccc}
\hline Fe\% & C\% & Si\% & Mn\% & Cr\% & P\% & S\% & O $_{\mathbf{2}} \%$ \\
\hline Rem. & 4.2 & 0.61 & 0.8 & - & 0.008 & 0.014 & 0.002 \\
\hline
\end{tabular}

Samples are heated up to $1000^{\circ} \mathrm{C}$ for a period of 20 minutes in thermal treatment furnaces using Argon gas to prevent any subsequent oxidation and then divided into four groups. Samples are prepared for accurate microscopic examination, hardness measurement and X-ray examination. Preparation processes included (cutting, smoothing, polishing and exposure), the Picral solution used consisting of $4 \%$ Picral acid in ethanol and as specified (ASTM SE407).

Figure 1 shows the exact crystal structure and Figure $2 \mathrm{X}$ ray examination of the base sample prior to treatment. The average hardness was 470HB (first group).

While the second group of samples was heated at 800, 950, $1000^{\circ} \mathrm{C}$ and for a time of between 15-240 min. All samples showed an accurate crystalline structure very similar to the original samples (without annealing), as there was no change in the exact composition, which means that no change from white to grey occurred completely or even localized. The only change that occurred on the surface was the carbon removal process because the heating process was not isolated from the normal atmosphere as shown in Figure 3.

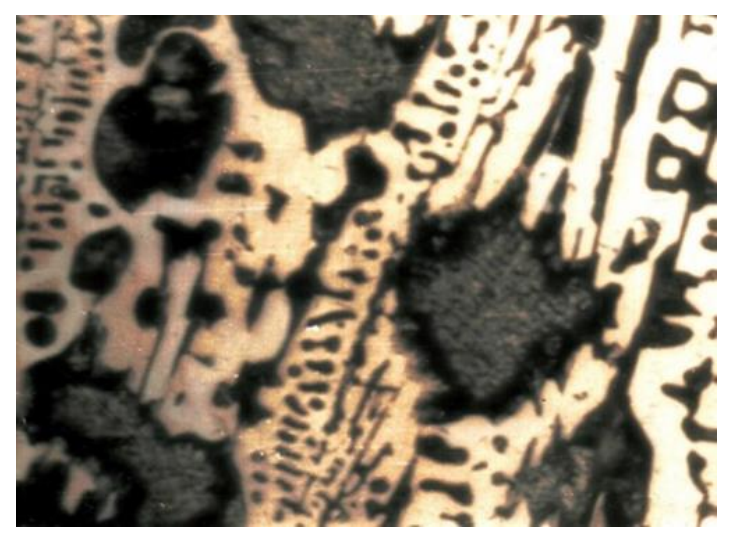

Figure 1. The exact crystal structure 


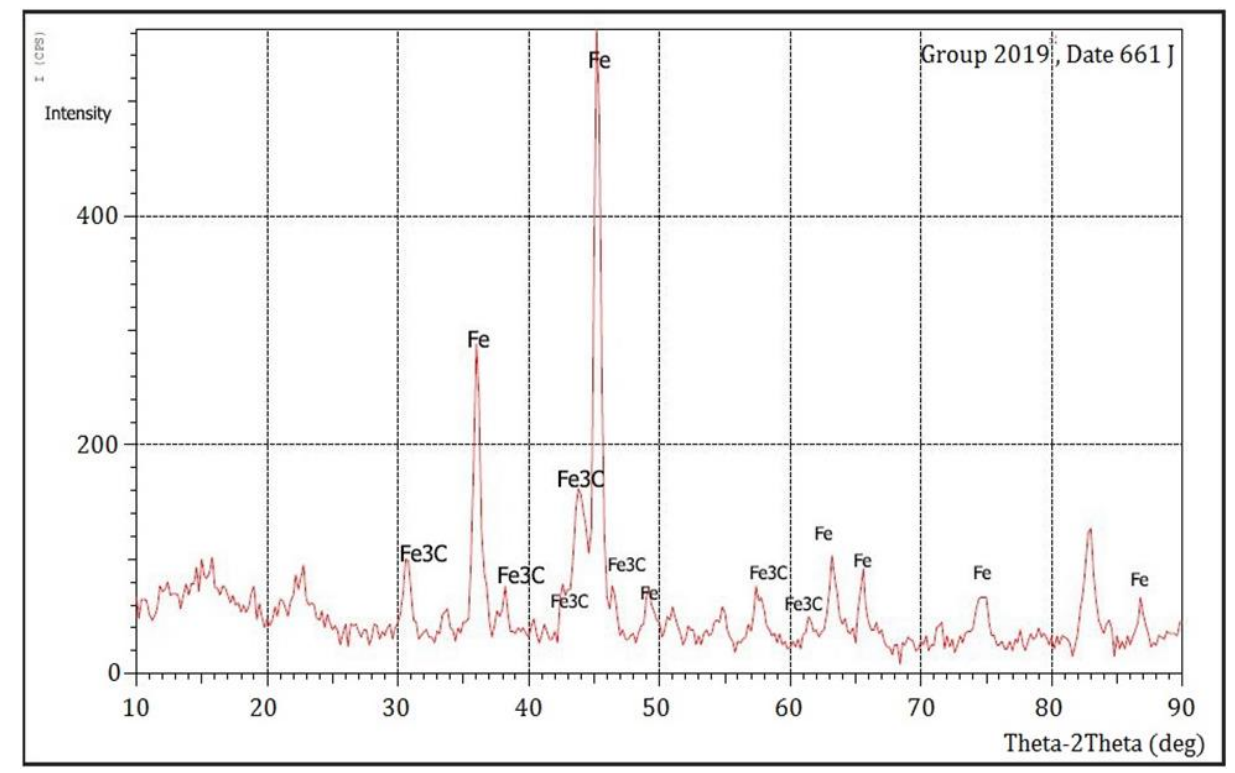

Figure 2. X-ray examination of the base sample before the heat agent

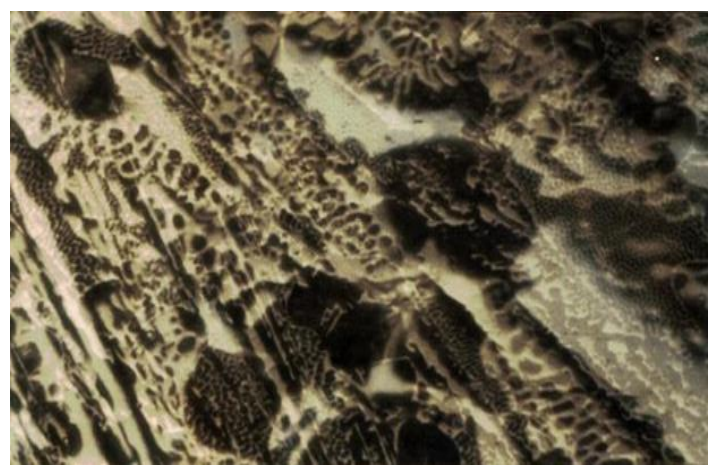

Figure 3. The stability of samples after heating

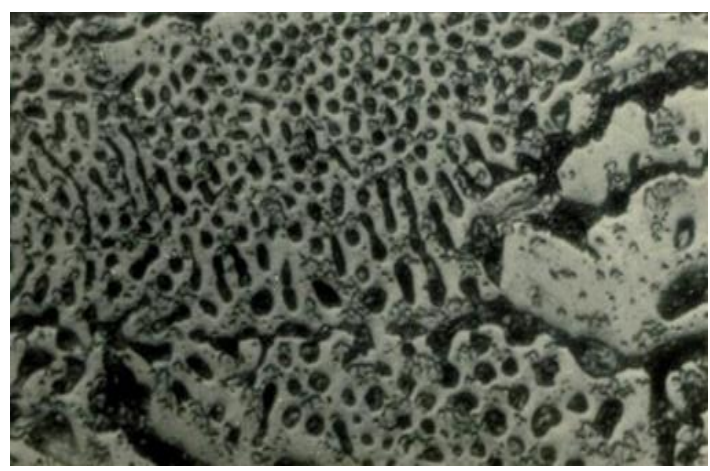

Figure 4. The crystal structure of white cast iron after heating $\left(1100^{\circ} \mathrm{C}\right)$ and for a period of (60-120min)
The third group, the samples are heated to temperatures $1100^{\circ} \mathrm{C}$ and for periods ranging from $60-120 \mathrm{~min}$. As well as, the exact composition is examined, which also looked similar to what is in the original samples and was also free from any transformation (Figure 4).

Experiments have shown that white cast iron is stable up to $1100^{\circ} \mathrm{C}$ and for the period indicated. The fourth group, the samples are heated at the same temperature $1100^{\circ} \mathrm{C}$ for a period of $10 \mathrm{~min}$, followed by taking the sample out of the oven and knocking it directly for one or more times using a hydraulic hammer, as shown in Figure 5 hammer specifications. Followed by measuring the percentage for formation as shown in Table 2.

By examining the crystalline structures of the fourth group and the different forming ratios from $20 \%$ to $60 \%$, it observed that the synchronization of the annealing and forming processes was accompanied by a deformation of the fine composition of the sample without causing carbonation (Figure 6).

And that there is a change in the pattern of cementite $\left(\mathrm{Fe}_{3} \mathrm{C}\right)$ distribution, where the lamellar shape turns into something similar to the mass at $60 \%$ as shown in Figure 7, which represents a change in the pattern of cementite distribution with an increase in the formation ratios in the white cast iron and X-ray examinations, Figure 8.

Figure 8 represents the behavior of X-ray diffraction when the white cast iron was completely transformed into gray cast iron due to the high forming processes, which exceeded the limits of $70 \%$ (the forming percentage).

Table 2. Hammer specifications and deformation percentage

\begin{tabular}{|c|c|c|c|c|c|c|}
\hline Alloy & & & Operation conditions & & & $\begin{array}{c}\% \% \\
\text { Formation } \\
=100 x \frac{L_{\circ}-L}{L_{\circ}}\end{array}$ \\
\hline & Hammer name & $\begin{array}{c}\text { Fallen hammer } \\
\text { weight kg. }\end{array}$ & $\begin{array}{c}\text { Maximum power in one } \\
\text { stroke kg.m }\end{array}$ & $\begin{array}{c}\text { Number of } \\
\text { hammers/min }\end{array}$ & $\begin{array}{c}\text { Horsepower } \\
\text { kW }\end{array}$ & \\
\hline 1 & \multirow{4}{*}{$\begin{array}{l}\text { Pneumatic } \\
\text { hammer }\end{array}$} & \multirow{4}{*}{165} & \multirow{4}{*}{270} & \multirow{4}{*}{190} & \multirow{4}{*}{24.11} & 20 \\
\hline 2 & & & & & & 40 \\
\hline 3 & & & & & & 60 \\
\hline 4 & & & & & & $70>$ \\
\hline
\end{tabular}




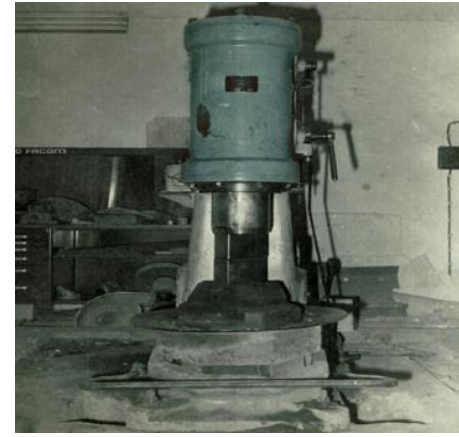

Figure 5. Hammer used in white cast iron methods heated at $1100^{\circ} \mathrm{C}$ for a period of $10 \mathrm{~min}$

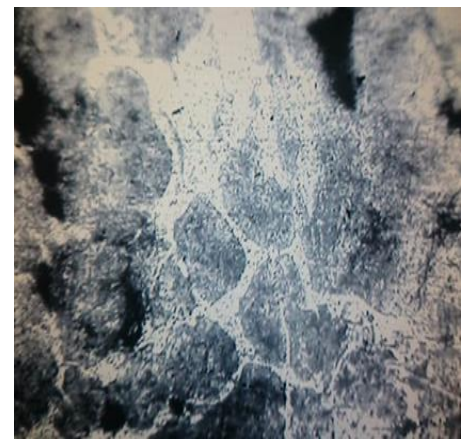

Figure 6. Model of the structure of cast iron at low forming ratios

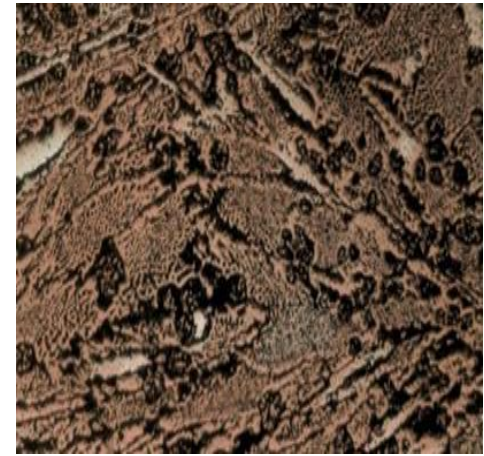

Figure 7. Model of the structure of white cast iron at the forming ratio $(60 \%)$

Therefore, the behavior completely changed from the previous form (Figure 2), here (Peack) due to cementite increased significantly and is widespread compared to B (Peack) referring to iron, where the transformation here is complete from white to gray. It should be noted here that Figure 2 shows the X-ray diffraction for the first sample which did not suffer from knocking or any thermal treatment.

When the percentage of formation increased by (greater than $70 \%$ ), a major shift occurred, as a complete and clear transformation from white cast iron to grey was observed, the graphite flakes appear to be completely clear as shown in Figure 9.

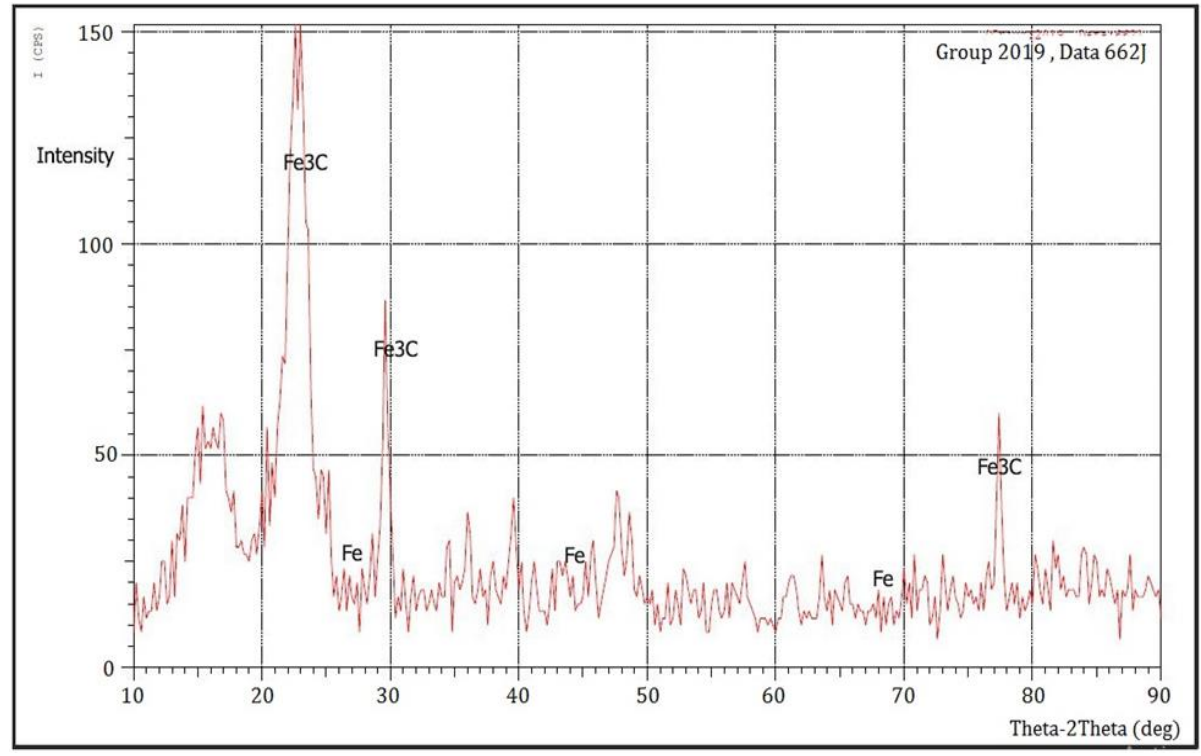

Figure 8. X-ray analysis of the white cast iron structure model at the forming ratio $60 \%$

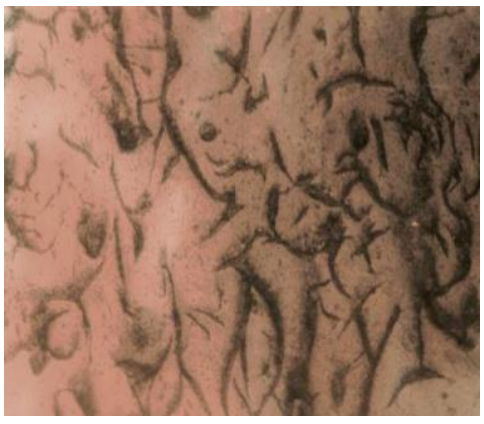

Figure 9. The white cast iron was largely grayed after high forming rates

\section{RESULTS AND DISCUSSION}

The current research reflects a new approach for turning white cast iron to grey and a process that can be described as simple and quick compared to conventional heat treatment methods. Also, this approach will shed light on the stages of the carbonation mechanism. From the Figures 1, 3, 4, it seems obvious that white cast iron cannot turn grey at the temperature $1100^{\circ} \mathrm{C}$ and with the annealing times (60-120 min.).

It is also assumed that the coordination of the annealing and shaping processes is followed by a deformation of the fine composition and does not induce any carbonation as shown Figures 6, 7. But when the formation percentages increase 
larger than 70\%, a sudden big change will occur (Figure 9).

First of all, we try to comparative analysis of the data before and after the knocking with the hammer. Figure 2 shows XRAY of the base sample without any thermal or mechanical treatment. It seems from this figure that the cementite extends along the section of the shape and there is a main PEAK representing iron. Furthermore, this is expected for the white cast iron sample, where the height of the PEAK of cementite is short and continuous because it is spread here in the form of strips.

Therefore, it is distributed unevenly in the iron floor. When moving to Figure 8, it seems that the shape and distribution differed as we notice the spread of PEAKS of cementite more and more severely compared to the previous one and there is a clear PEAK at the angle of 25 degrees. This indicates that the cementite is no longer continuous strips, but rather scattered broken strips are distributed unequally or homogeneously. Accordingly, breaking thick cementite strips into short, diffuse strips is considered the beginning of the next stage, and it is the breakdown of those tapes into free graphite tapes.

Through Figure 9, important results can be reached. The first is that there seems to be a complete and absolute change from white cast iron to grey, and it happens when some percentages of the composition are surpassed (more than 70\%).

The second is that the factors influencing the transformation process (carbonation) are very significant in the understanding of the transformation system since it is not possible to focus entirely on correct microscopic inspection. Table 3 shows the chemical composition of the last item.
Table 3. Chemical composition of the last item

\begin{tabular}{cccccccc}
\hline Fe\% & C\% & $\mathbf{S i} \%$ & $\mathrm{Mn} \%$ & $\mathrm{Cr} \%$ & $\mathbf{P \%}$ & $\mathrm{S \%}$ & $\mathbf{O}_{\mathbf{2}} \%$ \\
\hline Rem. & 4.11 & 0.60 & 0.75 & - & - & 0.010 & - \\
\hline
\end{tabular}

These findings are consistent with previous research in which a rapid and complete transition from white to grey happens at a development rate of more than $72 \%[11,15]$. The research discussed the most important factors concerning the carbonation function. It is known that this mechanism goes through (4) stages, which are: the time of the melting of cementite in Kama iron, the time of the movement of carbon atoms through iron and the crystallization of graphite, and finally the distribution of iron and silicon atoms away from graphite.

It was assumed that the diffusivity regulates the mechanism of transformation, that the diffusivity of iron and silicon and all other elements present cannot be the control factor in the process, as the activation energies of these elements in austenite have the same number, whereas the activation energy for carbon diffusion is the lowest. When measuring the diffusion distance $[\mathrm{L}]$ for $(\mathrm{Fe}, \mathrm{C})$ from the Eq. (1):

$$
L=\pi \sqrt{D t}
$$

At a temperature $\left(1100^{\circ} \mathrm{C}\right)$, where (D) is the coefficient of diffusion, as seen in Table 4 [11].

Table 4. Diffusion distance at $\left(1100^{\circ} \mathrm{C}\right)[11]$

\begin{tabular}{|c|c|c|c|c|c|c|}
\hline Elements & $D \circ \mathrm{cm}^{2} \mathrm{~s}^{-1}$ & Q. Kcal mol ${ }^{-1}$ & $X=\pi$ & $\overline{D_{\circ}} \exp ($ & $\left(\frac{-Q}{K T}\right)$ & $t, \mathrm{~cm}$ \\
\hline $\mathrm{C}$ & 0.01 & 27.0 & $\begin{array}{c}5 \mathrm{~s} . \\
5 \times 10^{-3}\end{array}$ & $\begin{array}{r}5 \mathrm{~min} \\
3.9 \times 10\end{array}$ & & $\begin{array}{c}3 \mathrm{hr} . \\
2.3 \times 10^{-1}\end{array}$ \\
\hline $\mathrm{Fe}$ & 58 & 74.2 & $6.6 \times 10^{-5}$ & $5.1 \times 10$ & & $3.1 \times 10^{-3}$ \\
\hline
\end{tabular}

Through these values, it can be inferred that the carbonation process is at $\left(1100^{\circ} \mathrm{C}\right)$ and takes place within a few minutes and is finished within (30 min.). While we did not note any phase of its carbonation in the above-mentioned temperature range over any period of time (15-240 min.) the volume of cementite had increased. It can be inferred from this that the diffusivity element of carbon or iron is not the primary factor in the carbonation process.

As for the crystallization of graphite, this can also be omitted as a limiting element in the process of transformation. This finding is consistent with previous studies $[16,17]$ that the growth rate is steady and continuous and moves from the point of origin, i.e., when the annealing time is zero (Zero time) it is considered to be the beginning of the transition (Zero time is considered to be the beginning of the reaction), but in the functional application, it did not find any change. Indeed, no procedure was conducted in this study when heated at $\left(1100^{\circ} \mathrm{C}\right)$ either for long or short periods of time.

The melting stage of cementite in austenite is known to regulate the mechanism of carbonation. Melting happens (immediately) at some percentages by hot impact formation (high forming ratio). The explanation is attributed, first of all, to the crystal composition of cementite and to the existence of the bonding between the atoms in the cementite crystal itself. Numerous experiments have shown [29] that the crystal structure of cementite is distinguished by the presence of two forms of bonds. The first is the bond between $(\mathrm{Fe}-\mathrm{C})$ which is covalent and the second between (Fe-Fe) which is metallic in nature. It is understood that the covalent bond is double the strength of the mineral bond, in addition to the fact that the crystal structure of cementite contains a group of prisms; the internal bond in it is covalent, while the prisms are linked by the mineral spur. The metal band enables the plastic shaping mechanism so that the prisms can move through the creation while maintaining the covalence intact within them (thus the prisms do not break). The forming can take place if the sliding is at (010) levels.

This can be derived from the existence of the structure of the layers of atoms inside the prisms. This ability is consistent with what other researchers have recorded [30] and thus, due to the low rate of forming of cementite crystals due to hot shocks, there could be a mutual movement of prisms at levels (010) while the interconnection between these prisms remains intact. But when the deformation ratios reach a certain limit, the covalent bond (within the prisms) would not be able to tolerate and break down. This describes the quick and wide breakdown of cementite and the abrupt introduction of carbonation.

\section{CONCLUSIONS}

Presented study conclusions can be drawn as follows: 
i. $\quad$ Temperature annealing $\left(1100^{\circ} \mathrm{C}\right)$ for a $60 \mathrm{~min}$ does not induce any total or even localized carbonation phase.

ii. The formation resulting from hot impact and even at low forming concentrations does not induce any total or even localized carbonation.

iii. When the shape resulting from the hot impact reaches those limits (greater than $70 \%$ ) in significant quantities; a rapid and complete transition phase takes place from white cast iron to grey.

iv. The main element in the transition process is the solubility of cementite in the Kama iron.

\section{ACKNOWLEDGMENT}

The authors would like to thank Dr. Raheem K. Ajeel (raheem@ukm.edu.my) for his assistance in completing and publishing this work.

\section{REFERENCES}

[1] Ibrahim, K.M., Ibrahim, M.M. (2014). Heat treatment in high chromium white cast iron Ti alloy. Journal of Metallurgy, 2014: 1-9. https://doi.org/10.1155/2014/856408

[2] Farah, A.F., Crnkovic, O.R., Canale, L.C.F. (2001). Heat treatment in high $\mathrm{Cr}$ white cast iron $\mathrm{Nb}$ alloy. Journal of Materials Engineering and Performance, 10(1): 42-45. https://doi.org/10.1361/105994901770345321

[3] Filipovic, M., Kamberovic, Z., Korac, M., Gavrilovski, M. (2013). Microstructure and mechanical properties of $\mathrm{Fe}-\mathrm{Cr}-\mathrm{C}-\mathrm{Nb}$ white cast irons. Materials \& Design, 47: 41-48. https://doi.org/10.1016/j.matdes.2012.12.034

[4] Keil, B., Devletian, J. (2011). Comparison of the mechanical properties of steel and ductile iron pipe materials. In Pipelines 2011: A Sound Conduit for Sharing Solutions, pp. 1301-1312.

[5] Razumakov, A.A., Stepanova, N.V., Bataev, I.A., Lenivtseva, O.G., Riapolova, I.I., Emurlaev, K.I. (2016). The structure and properties of cast iron alloyed with copper. Materials Science and Engineering, 124(1): 012136. $899 X / 124 / 1 / 012136$

[6] Herring, D. (2014). Atmosphere Heat Treatment: Principles, Applications, Equipment. BNP Media.

[7] Chakrabarty, I. (2017). 2.10 heat treatment of cast irons. Comprehensive Materials Finishing, 2: 2446-287. https://doi.org/10.1016/B978-0-12-803581-8.09192-X

[8] Chen, X., Li, Y. (2010). Effect of heat treatment on microstructure and mechanical properties of high boron white cast iron. Materials Science and Engineering: A, 528(2): 770-775. https://doi.org/10.1016/j.msea.2010.09.092

[9] Abdel-Aziz, K., El-Shennawy, M., Omar, A.A. (2017). Microstructural characteristics and mechanical properties of heat treated high-Cr white cast iron alloys. International Journal of Applied Engineering Research, 12(14): 4675-4686.

[10] Zeytin, H.K., Yildirim, H., Berme, B., Duduoĝlu, S., Kazdal, G., Deniz, A. (2011). Effect of boron and heat treatment on mechanical properties of white cast iron for mining application. Journal of Iron and Steel Research
International,

18(11):

31-39.

https://doi.org/10.1016/S1006-706X(11)60114-3

[11] Zhou, S., Shen, Y., Zhang, H., Chen, D. (2015). Heat treatment effect on microstructure, hardness and wear resistance of Cr26 white cast iron. Chinese Journal of Mechanical Engineering, 28(1): 140-147. https://doi.org/10.3901/CJME.2014.0620.116

[12] Fernández, I., Belzunce, F.J. (2008). Wear and oxidation behaviour of high-chromium white cast irons. Materials Characterization, 59(6): 669-674. https://doi.org/10.1016/j.matchar.2007.05.021

[13] Gelfi, M., Pola, A., Girelli, L., Zacco, A., Masotti, M., La Vecchia, G.M. (2019). Effect of heat treatment on microstructure and erosion resistance of white cast irons for slurry pumping applications. Wear, 428-429: 438-448. https://doi.org/10.1016/j.wear.2019.03.011

[14] Opapaiboon, J., Ayudhaya, M.S.N., Sricharoenchai, P., Inthidech, S., Matsubara, Y. (2019). Effect of Chromium content on heat treatment behavior of multi-alloyed white cast iron for abrasive wear resistance. Materials Transactions, $\quad 60(2)$ : 346-354 https://doi.org/10.2320/matertrans.M2018318

[15] Inthidech, S., Yamamoto, K., Matsubara, Y. (2020). Effect of tungsten equivalent on heat treatment behavior of semi-multi-alloyed white cast iron for abrasive wear resistance. International Journal of Metalcasting, 1-12. https://doi.org/10.1007/s40962-020-00449-8

[16] Meebupha, T., Inthidec, S., Sricharoenchai, P., Matsubara, Y. (2017). Effect of molybdenum content on heat treatment behavior of multi-alloyed white cast iron. Materials Transactions, 58(4): 655-662. https://doi.org/10.2320/matertrans.M2016396

[17] Sarac, M.F., Dikici, B. (2019). Effect of heat treatment on wear and corrosion behavior of high chromium white cast iron. Materials Testing, 61(7): 659-666. https://doi.org/10.3139/120.111382

[18] Boccardo, A.D., Dardati, P.M., Celentano, D.J., Godoy, L.A. (2017). Austempering heat treatment of ductile iron: Computational simulation and experimental validation. Finite Elements in Analysis and Design, 134: 82-91. https://doi.org/10.1016/j.finel.2017.06.002

[19] Sil'man, G.I. (2005). Alloyed white iron with composite structure. Metal Science and Heat Treatment, 47(7-8): 343-348. https://doi.org/10.1007/s11041-005-0076-5

[20] Stan, S., Chisamera, M., Riposan, I., Stefan, E., Neacsu, L., Cojocaru, A.M., Stan, I. (2019). Simultaneous thermal and contraction/expansion analyses of cast iron solidification process. Journal of Thermal Analysis and Calorimetry, 138(4): 2529-2540. https://doi.org/10.1007/s10973-019-08595-w

[21] García-León, R.A., Acevedo-Peñaloza, C., QuinteroQuintero, W. (2020). Mechanical evaluation of the nodular gray cast iron with the application of thermal treatments. Journal of Xi'an University of Architecture \& Technology, 12: 1868-1876.

[22] Abdellah, M.Y., Hassan, M.K., El-Ainin, H.A. (2014). Plasticity and formability controlling of cast iron using thermo-mechanical treatment. American Journal of Materials Engineering and Technology, 2(3): 38-42. https://doi.org/10.12691/MATERIALS-2-3-3

[23] Kante, S., Leineweber, A., Holst, A., Buchwalder, A. (2019). Low-temperature annealing and graphitizing of white-solidified low-alloy cast irons. Materialwissenschaft und Werkstofftechnik, 50(6): 682- 
695. https://doi.org/10.1002/mawe.201800169

[24] Jia, X., Huang, Y., Zuo, X., Liu, Y., Chen, N., Rong, Y. (2019). High hardness-toughness and wear resistance of white cast iron treated by a multicycle quenchingpartitioning-tempering process. Heat Treatment and Surface Engineering, 1(1-2): 57-62. https://doi.org/10.1080/25787616.2018.1560148

[25] Liu, Y.C., Zhan, X.H., Yi, P., Liu, T., Liu, B.L., Wu, Q. (2018). Research on the transformation mechanism of graphite phase and microstructure in the heated region of gray cast iron by laser cladding. Optics \& Laser Technology, 100: https://doi.org/10.1016/j.optlastec.2017.09.051

[26] Chen, X., Zhao, L., Zhang, W., Mohrbacher, H., Wang, W., Guo, A., Zhai, Q. (2019). Effects of niobium alloying on microstructure, toughness and wear resistance of austempered ductile iron. Materials Science and Engineering: $\quad$ A, $\quad 760$ : 186-194. https://doi.org/10.1016/j.msea.2019.05.100

[27] de Souza, B.V., Ribeiro, T.M., Francois, A., dos Santos,
C.A. (2018). Austempering heat treatments of ductile iron using molten metal baths. Materials and Manufacturing Processes, 33(15): 1667-1673. https://doi.org/10.1080/10426914.2018.1424909

[28] Tadesse, A., Fredriksson, H. (2018). The effects of carbon on the solidification of nodular cast iron-its study with the help of linear variable differential transformer and microstructural analysis. International Journal of Cast Metals Research, 31(2): 108-117. https://doi.org/10.1080/13640461.2017.1377382

[29] Collin, N. (2014). Thermo-Mechanical Fatigue of Castiron for Engine Applications. Master of Science Thesis Stockholm, Sweden 2014.

[30] Chulkina, A.A., Ul'yanov, A.I., Gorkunov, E.S. (2008). The role of cementite in the formation of magnetic hysteresis properties of plastically deformed high-carbon steels: III. Magnetic properties of patented wire made of steel 25. Russian Journal of Nondestructive Testing, 44(5):

309-317. 